\title{
Discussion on the Textbook Construction of Computer Technology Appli- cation Professional in Vocational Colleges
}

\author{
Wei Ma \\ Qinhuangdao Institute of Technology, 066100 Qinhuangdao Hebei, China
}

\begin{abstract}
After analyzing the actual problems with the textbook construction of computer major in the vocational colleges nowadays, the author puts forward some advice on some aspects. These suggestions can satisfy students' needs through long-term teaching process, at the same time they have certain significant reference to textbook construction in vocational colleges.
\end{abstract}

Keywords. professional education; computer; textbook construction

\section{Introduction}

As an important part of the higher education system, the development of higher vocational education in our country, to some extent, satisfy the demand about social and economic development of different levels talents cultivation. However, textbook construction, as one of the three basic building materials construction, is far behind the pace of development of higher vocational education.

Textbook is the basis of the teaching resources, and it is the main reflect to the teaching content, teaching methods as well as teaching mode. It is also one of the most important content of higher vocational teaching reform. So how to promote the reform of courses and textbooks and develop and write distinctive vocational education textbook is the key point. It largely marks the depth of the teaching reform, reflects the concept of modern vocational education, and shows us the teaching quality of higher vocational education.

\section{The current situation of higher voca- tional computer professional teaching textbook construction}

\subsection{The applicable targets are not clear enough}

Currently the higher vocational computer textbooks are mostly "express", that is directly cut, adjust and process the undergraduate computer course textbook. Most of the textbooks are compiled by a group of university teachers organized by the press, combined with their own teaching experience. The contents of these materials are mostly full but general, just build a generic framework of theoretical knowledge. The lack practical knowledge access system, besides, they do not meet the vocational needs about personnel training, and does not reflect a clear application to the characteristics and requirements vocational education.

\subsection{Content updates lag behind}

The textbook construction needs to prepare multiple work areas, typesetting printing, distribution and other work, so it is easy to generate a time lag. Especially for the rapid development of the IT industry, the content of computer textbook is divorced from reality of regional industry and professional development, and can't be updated timely and flexibly like the information provided on the network. Thus many professional teachers do not perform contentbased textbook, and students believe that textbook does not produce a proper role in learning.

\subsection{Does not highlight "occupation" of higher vocational education}

The lack of cohesion between the content and professional technical standards is becoming more and more prominent. One of the characteristics of higher vocational education is "double certificates" system, which requires students' graduate diploma and the corresponding professional skills certificates. So it requires students to master the basic skills in the professional field actual work and new technology on the basis of necessary basic theory and professional knowledge. The type of the current computer majors can obtain certificates of many, including the National Computer vocational skills certification series, the National Information Technology Engineer Project Series as well as various industry sectors certification series, at present, there are many kinds of certificates the computer professional students can pass, includ- 
ing the National Computer vocational skills certification series, the National Information Technology Engineer Project Series as well as various industry sectors certification series. Throughout all kinds of higher vocational textbooks, none is able to achieve the relevant with professional skills certificate or accreditation standards for effective convergence.

\subsection{Lack of systematic practice of teaching}

Computer practice teaching weigh heavily and the proportion of theoretical teaching should meet or greater than $1: 1$, the textbook building in the teaching reform should also occupy a very important position. In fact, the applicable professional courses on computer training textbook rarely, mostly with heretical teaching part of the design verification experiment project, and standardization of teaching is not strong, lack of unified standards. Although some institutions have written some training guide books, but there are still some problems, like relatively simple content, knowledge is not perfect, practically weak. Teaching practice needs to form independent system, therefore it should cooperate with the training goal of higher vocational education.

\subsection{A single teaching material form}

In the realization of the teaching methods from the traditional "chalk + blackboard" form to the development of multimedia technology, textbook building just stop at a single form of paper books, and it does not make full use of modern means of fused elements more diverse in the construction of textbook. We still need the formation to form a complete set of products. According to the current trend of teaching, teaching textbook construction will be the development direction of construction of teaching material.

\section{The construction of teaching materials}

\subsection{The construction of curriculum system}

Related majors in higher vocational colleges of the computer application technology, mainly cultivate highquality skilled personnel, for software industry as a service in the software development industry software developers. The course system of computer application technology is based on professional post in the process of practical production, it is repeatedly discussed and demonstrated by practice expert seminar, with a strong occupational characteristics. Textbook building should serve this system, and it should organize the content by the theory and practice of knowledge organization and select training projects to develop the textbook in schoolenterprise cooperation.

\subsection{Project for production line organization computer textbook contents.}

Determination of professional teaching content must be based on professional training objectives. Furthermore, it should be combined with the typical tasks analysis, set the actual production as the main line of the project, the occupational status of work required during the professional skills into the teaching content, embody knowledge of project tasks for the center systematic and holistic work. Because of the large number of computer language functions, procedures, classes, variables such as grammar, computer science teaching in the student's learning process, more is used as a guide and information tool. In addition to guiding students to complete the complete project, we still need to pay attention to the development of self-study ability, guide students to independent data access tools, to complete the project tasks and expansion of knowledge. Therefore we can organize the depth and breadth of the textbook with the project tasks as the main line, to better reflect the vocational education "enough for the degree, practice-oriented" principle, and vocational and technical standards.

\subsection{Institute-enterprise cooperation and devel- opment}

Vocational education textbook building is not only different from the discipline of knowledge building in undergraduate education, but also from writing the preservice training manuals. However it is based on the talents growth rules, professional work requirements, school teaching selection of content and design, jointly planned and developed by the business line staff and school teachers. By joining the national vocational standard, absorbing the teaching resources of the enterprise, combining the real projects, cases, professional norms and procedures with the teaching knowledge, a complete teaching content is formed. It provides students with a more professional, operational and informational for the textbook, at the same time it broaden the field of vision, makes the teaching better integrate with the professional jobs.

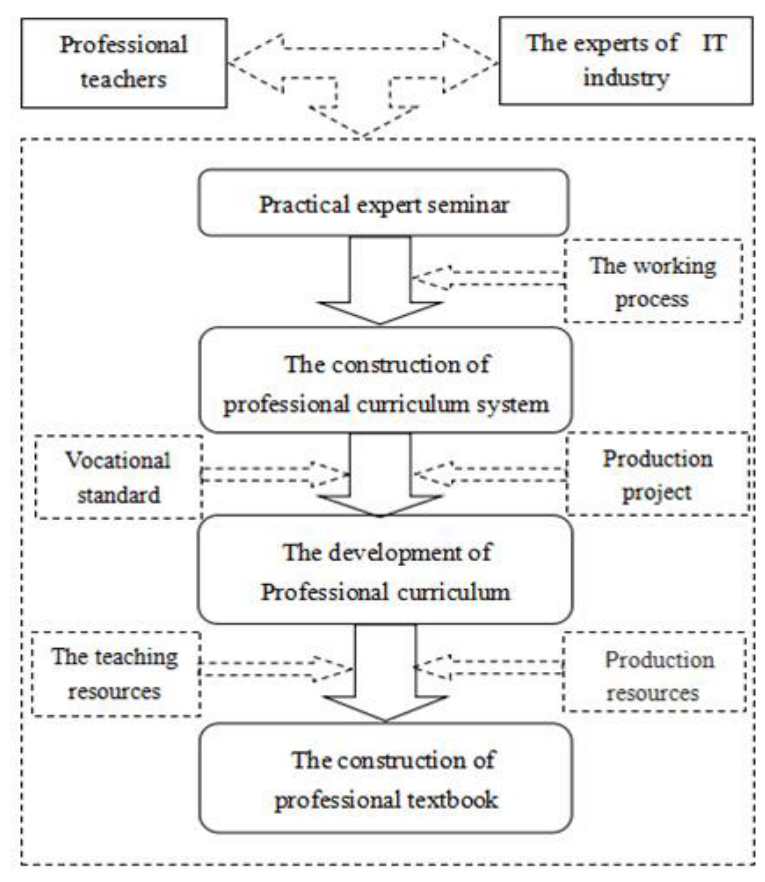

Figure 1. The flow chart of computer professional textbook. 


\subsection{Build heretical knowledge on the demand of the professional quality training}

We need to change the existing vocational computer textbook "first theory, after authentication" teaching arrangements, in order to cultivate the students' comprehensive professional quality as the theme, the structure of the construction of a reasonable theory teaching and practice teaching system, realize the theory of knowledge "demand assignment". According to "software project decomposition of tasks - need to have the theoretical and practical knowledge - task to achieve - to expand knowledge - evaluation summary" model expands to project-driven. In the process of implementing the task decomposition into the corresponding theory knowledge, we should cultivate students' the professional ability, theoretical knowledge and practical knowledge of twoway and interactive relationship. By practicing operation thirst for knowledge, and theory of knowledge learning, teachers should help students to gradually achieve the overall goals, until the project is completed. In such a cycle students are helped to understand the knowledge in the process of generation and development process, form the good habit of scientific spirit and innovative thinking, cultivate to gather information, analyze problems, acquire new knowledge of professional ability of cooperation.

\subsection{Focus on cultivating the students' ability of sustainable development}

Since IT industry development is so rapid that computer software development industry technicians must have self-knowledge about the quality of self-development capability which requires us to guide the student to build up the idea of lifelong education, to cultivate the students' ability of sustainable development. In computer professional textbook construction, besides the introduction of the necessary theoretical and practical knowledge content, we should provide more ways and clues, and guide students through various means to collect, analyze and sort out the related information, to expand the professional knowledge, study vision through a textbook to expand to a wider range of space, form a good habit of autonomous learning and constantly updated knowledge.

\subsection{Construction of three-dimensional textbook}

In a growing network course construction, three-dimensional textbook construction is the overall trend of higher vocational teaching material construction, but that does not mean that can only be realized by incorporating the text, pictures, sound, video and other multimedia elements into the textbook construction. Textbook construction must focus on the whole and it should be planned and designed by making full use of modern technology. The involvement of various elements can strengthen the interactive aspects of the settings to achieve the construction of a series of teaching materials, so the performance of materials will be more interesting to read.

\section{References}

1. Shen, H.J., Shen, Y., Sun, L. \& Xuan, L.F. Thinking of the construction of higher vocational textbook [J]. Education and Profession, 2006, 36:117.

2. Wu, B.Z. Thinking about some issues of higher vocational textbook construction [J]. Mechanical Professional Education, 2001, 9:36.

3. Li, B. The revelations from a foreign vocational education textbook [J]. China Vocational and Technical Education, 2004, 15:37.

4. Jiang, D.Y. Education level and education content extension [J]. Journal of Beijing Union University, 2004, 1:9.

5. Ren, L.H. Analysis of the Construction of Higher Vocational Education Teaching Material Problems and Thinking [J]. Vocational Education Research, 2008, 8:31. 